MEASURING GAINS IN OPERATIONAL EFFICIENCY FROM INFORMATION TECHNOLOGY:

A STUDY OF.THE POSITRAN DEPLOYMENT AT HARDEE'S INC.

\author{
by \\ Rajiv D. Banker \\ Robert J. Kauffman \\ Richard C. Morey
}




\title{
MEASURING GAINS IN OPERATIONAL EFFICIENCY FROM INFORMATION TECHNOLOGY: \\ A STUDY OF THE POSITRAN DEPLOYMENT AT HARDEE'S INC.
}

\author{
by \\ Rajiv D. Banker \\ Carlson School of Business \\ University of Minnesota \\ Minneapolis, Minnesota 55455 \\ Robert J. Kauffman \\ Leonard N. Stern School of Business \\ New York University \\ New York, New York 10003 \\ and \\ Richard C. Morey \\ Center for Health Services Research \\ University of Cincinnati \\ Cincinnati, Ohio 45221 \\ May, 1991 \\ Center for Research on Information Systems \\ Information Systems Department \\ Leonard N. Stern School of Business \\ New York University
}

\section{Working Paper Series}

STERN IS-91-9

Published in the Journal of Management Information Systems,

Vol. 7, No. 2 (Fall 1990), pp. 29-54. 
RATV D. BANKER holds the Arthur Andersen Chair in Accounting and Information Systems at the Carlson School of Management, University of Minnesota, and is Professor of Management (on leave) at Camegie-Mellon University. He received a doctorate from Harvard Business School in planning and control systems. He currently serves on the editorial boards of six journals and as co-editor of the Journal of Productivity Analysis. He has published over 40 refereed articles. His research interests include strategic cost management, measuring the business value of information technology, assessing software development and maintenance productivity, and the economics of information.

ROBERT J. KAUfFMAN is Assistant Professor at the Stem School of Business, New York University, where he has taught since 1988. He completed his master's degree in International Affairs at Comell University, and was later employed as an international lending and strategic planning officer at a large money center bank in New York City. He received a doctorate in Information Systems from the Graduate School of Industrial Administration, Carnegie-Mellon University in 1988. His current program of research involves developing new methologies for measuring the business value of a broad spectrum of information technologies, using techniques from management science and economics.

RICHARD C. MOREY is Professor and Director of Center for Health Services Research, a joint effort of the business and medical schools at the University of Cincinnati. He received his Ph.D. from the University of California at Berkeley in Operations Research. His prior associations include Duke University, the Institute for Defense Analysis, and Stanford Research Institute. He is also a founder and principal of Control Analysis Corporation, a consulting firm based in Palo Alto, CA. He has taught as an adjunct at Stanford University and George Mason University. His current research interests are in the areas of productivity and efficiency analysis, and manpower allocation. He is an associate editor for Naval Research Logistics Quarterly and the Journal of Cost Analysis, and has authored over 60 refereed publications.

ABSTRACT: This paper presents a new approach to measuring the input productivity gains from information technology (IT) in complex managerial environments. The approach is illustrated in the context of a study of a pilot deployment at Hardee's Inc. of a new cash register point-of-sale and order-coordination technology called "Positran." The method employs data envelopment analysis (DEA) and nonparametric production frontier hypothesis testing to determine whether the performance of restaurants that have deployed Positran is better, on average, than for those that have not. The design of the study is of special interest, because it approximates a controlled experiment. Our results show that Positran helped to reduce input materials costs, since restaurants that deployed the technology were less likely to be inefficient. It is further possible to characterize the class of restaurants for which the relationship holds. Operational efficiency measures such as the ones we have developed provide managers with the opportunity to implement deployment strategies for new ITS in order to maximize value.

KEY WORDS AND PHRASES: measuring value of information systems, operational efficiency, productivity gains due to information systeins. 


\section{Introduction}

\subsection{The Problem: Measuring IT Value in a Service Industry Setting}

Today, senior managers in service-industry firms are faced with making decisions about how to spend historically large information technology (IT) budgets without the comfort and guidance of systems of performance measurement that are broadly accepted in practice and well grounded in theory. As a result, there is much confusion about how the measurement of business value impacts of $\pi$ should actually be carried out. For example, the results of the American Banker 1988 Managing Technology Survey [37] showed that 55 percent of 188 senior executives in bank operations believed that the returns on their investments in IT were either good or excellent, although one-half of them reported that their firms did not have any formal systems in place to measure. Similar results were also found in an Index Group survey of 240 senior is managers for a broader cross-section of industries. In fact, Computerworld, commenting on the Index Group study, reported that only one in ten of the executives polled indicated that he/she knew how to evaluate adequately the business value of $\mathrm{IT}$ investments (November 8, 1988, p. 8).

Although investments in information technology made by large service-industry corporations can result in a variety of strategic impacts, the kinds that most senior managers probably feel they best understand are those that lead to relatively direct operating-cost savings, and are thus readily measurable. In other circumstances, measurement by itself does little to help management understand the value that $\mathrm{IT}$ can create in a firm's business operations. Instead, the justification for an investment in $T$ may develop out of a firm's beliefs about how it must respond to recent moves by its competitors just to stay competitive. In addition, rapid changes in technology, customer demand, the competitive environment, and the structure of the industry force managers to take risks and deal with uncertain future outcomes that increase the variance on the potential return to any investment $[19,21]$.

For many large and well-managed financial and nonfinancial industry companies, the days of easily measurable payoffs from automating operations are long gone. Major corporate investments in $\Pi$ that lead to operating cost reductions will be made 
with the goal of more carefully controlling the effects of previous investments in $\mathrm{Tr}$ and enhancing the effects of other programs that were meant to improve productive efficiency. In this paper, we present a new approach to understanding the leverage $\mathrm{IT}$ investments can have in improving efficiency in production.

\subsection{The Case: Hardee's Positran-Promoting Operating Efficiency, Product Differentiation, and Product Quality with IT}

Our approach is presented in the context of a case study of "Positran," Hardee's Inc.'s cash register point-of-sale and order-coordination system, which is now widely deployed among its more than 800 company-owned and 2,300 franchised units. In addition to providing support for a restaurant's order-taking and order-preparation activities, management intends Positran to support the firm's ability to deliver an innovative menu of products directly and to maintain the highest levels of product and service quality for its consumers.

Most observers would agree that product differentiation can make or break a competitor in a service industry. Nowhere is this more true than in the fast-food industry, where a couple of percentage points in national market share can translate into tens of millions of dollars of revenue, and the difference between a large operating profit or loss. Carol Levy, an analyst for Shearson Lehman Hutton who follows Hardee's performance, comments:

The [fast-food] industry is so competitive that you never have a unique product. If you do, you have it for three months max. All that really differentiates you is management, and Hardee's is running their business well. [29, p. D4]

If the quality of management really differentiates a fast-food firm, then consider the background of the present study. Positran was a pilot $I T$ deployment effort that represents as close to a controlled experiment on the value of $\mathrm{Tr}$ as is possible in most industry settings. Hardee's management chose to deploy Positran in a set of restaurants in which it was expected to perform well, and another set where the performance expectations were less optimistic. In effect, management was funding two treatment groups, and they allowed us to study a control group of restaurants where the technology was not deployed. This control group included restaurants exhibiting the same characteristics as those of restaurants that were expected to leverage the presence of Positran, as well as some that were not, across a market area with broadly similar demographic attributes. The results of this study suggest how much can be learned about the operational efficiency of a fast-food restaurant and an IT deployed to improve it. They also provide feedback to Hardee's management on an initially controversial and expensive IT deployment that is now at the heart of the firm's comprehensive point-of-sale data capture and information-reporting systems.

\subsection{Outline of the Paper}

The remainder of the paper is organized as follows. Section 2 presents our perspective on prior approaches to the measurement of firm efficiency and $I T$ vatue in the Is 
literature. We argue that a method is needed to capture the impact of IT on operating efficiency, when operating efficiency is potentially influenced by multiple factors in a complex operating environment. Section 3 presents a competitive analysis of Hardee's position in the burger segment of the fast-food industry, and the role that $\mathrm{IT}$ plays in helping it to strengthen its competitive position. The section also provides descriptive background on Positran itself, and management's rationale for investing in a technology to control materials waste while delivering a more diverse product mix. We discuss how it was deployed, how it integrates the cash-register, food-preparation, and food-delivery systems in a typical Hardee's restaurant, and what its intended performance effects were. We also describe the components of Hardee's materials input cost function, and the data set used to develop the results presented later in the paper.

Section 4 lays out an operational efficiency evaluation model that incorporates a term for "random" inefficiency. Random inefficiency (which we discuss in greater detail in that section) can stem from a number of possible sources, including the absence of $\mathrm{rr}$. We also discuss how this model can be evaluated using data envelopment analysis (DEA). Finally, we discuss the set of variables used to get a reading on the productivity impacts of Positran. Section 5 details the hypotheses we wished to test, our results, and their managerial significance. We conclude the paper with a review of our findings, some remarks about the limitations of our approach, and some directions for future research.

\section{Rethinking Efficiency Measurement for IT}

AN IN-DEPTH UNDERSTANDING OF INTERMEDIATE PRODUCTION is crucial to enSUTing that management deploys $\mathrm{IT}$ in a manner that maximizes its competitive and operational value. By intermediate production process, we refer to production within a firm that leads to the creation of goods and services, rather than their economic value. The latter is only determined when they are sold on the market. The environments in which intermediate production occur are formalized by Porter's value chain: inbound logistics, operations, outbound logistics, marketing and sales, and after-sales service [31]. Building on the idea of the value chain, Cash, McFarlan, and McKenney [14], for example, suggested a typology of potential impacts of $\Pi$, including building barriers to entry, building customer switching costs, changing buyer-supplier power relationships, and providing a basis for the creation of new products. Shaw [32] has discussed how to recast the value chain for application in service-industry companies, to provide other specific avenues along which management can explore the value of Ir. One can examine whether the outputs of the process have been produced efficiently in each part of the value chain.

\subsection{Perspectives on Firm Efficiency and IT Value}

Recent research on IT performance evaluation has emphasized the need to investigate intermediate production as a means to understand how Ir leads to the creation of 
business value. (For example, see the papers by Benham [12], Crowston and Treacy [20], Banker and Kauffman [7, 8,9], Kauffman and Kriebel $[24,25]$, and Parker and Benson [30].) This body of work reflects a recognition among researchers that it is methodologically quite difficult to develop robust measures linking IT investments to bottom-line impacts, without taking some pains to capture how the "conversion" from investment to value occurs, and whether it is effective. (For a fuller discussion of the concept of "conversion effectiveness," see Weill and Olson [36].)

Earlier studies by Stabell [34], Chismar and Kriebel [16], and more recent work by Harris and Katz [23] and Loveman [27], have taken a different approach, concentrating on strategic business-unit and firm-level aggregate analysis. At this level, however, Ir has been shown to provide few concrete payoffs to justify the expenditures, although there is a wealth of anecdotal evidence suggesting that some major investments in IT have paid off handsomely [19]. These results argue in favor of research approaches that focus on the IT-performance link more directly than a business-level analysis.

We support the argument that the science of measuring the effectiveness of $I T$ investments will improve through the application of multiple approaches that build on the experience gained and methods used in the studies mentioned above. (For a more complete review of the methods associated with $\mathrm{IT}$ value measurement, see Kauffman and Weill [26] and Carlson and McNurlin [13].) These include both organizational [35, $36]$ and economic process models $[1,11]$ and the use of case-by-case investigation of IT investments $[17,18]$. We believe that additional consideration should be given to the theory base for measuring how $\Pi$ influences efficiency, especially in the inbound and outbound logistics, and operations segments of the value chain.

In our current program of research on measuring $\Pi \mathrm{r}$-related gains in firm performance, we distinguish between "competitive efficiency" and "operational efficiency." Competitive efficiency measures describe the relationship between technology investments and other major firm-level expenditures, and bottom-line impacts, such as revenues, profitability, return on investment (ROI), and retum on assets, among others. Thus, firms exhibiting a high level of competitive efficiency tend to do better in terms of these indicators than other firms that deploy similar levels of resources.

Based on our definition, the firm- and business-level studies mentioned above can be broadly classified as competitive efficiency analyses of $I T$ investment. IT plays an important role in helping some of these firms to secure better performance than their competitors, but competitive efficiency measures alone do little to explain how some firms benefit, and to what extent. As we observed above, such highly aggregate measures sometimes sidestep the real measurement problem of identifying the contribution of $\Pi$, since there will be many influences of firm-level performance that will confound the effect of $\mathrm{rr}$. And, even when Ror is of greatest interest, potential users of the results and the methods employed in those studies need to bear in mind that they are meant to be descriptive rather than normative. :

Operational efficiency measures describe IT performance in intermediate production processes. They provide a means to gauge whether conversion of $\Pi$ investments into business value is occurring in the segments of the service value chain most affected by $\mathrm{rr}$. This is where management efforts to improve operational controls are 
centered, so it makes sense that $\mathrm{Tr}$ performance measures should either directly relate to, or be derived from, the operations the IT supports. Utilizing operational efficiency measures also makes a lot of sense when comparing one unit of a corporation with another. It is usually reasonable to assume that in order to keep costs under control, most corporations attempt to duplicate intermediate production processes across different units of the firm. Comparing operating units can yield targets for performance and suggests dimensions along which efforts to improve control of the operation can be made.

\subsection{Assessing IT's Impact on Efficiency in Complex Managerial Environments}

Having a method at hand to measure IT-related gains in input efficiency in complex production settings is of particular interest to us, since their complexity makes identifying the factors that lead to improvements in operational control more difficult. By complex production settings, we refer to segments in the value chain in which $I T$ is just one among a number of factors in the managerial environment that can affect the use of resources in the production of physical or service outputs. Although $\mathrm{Ir}$ may affect the outcome, it will be difficult to distinguish its contribution from those of other factors present in the managerial environment. When $\mathrm{Ir}$ is used to support production, its value can be derived from the extent it improves the likelihood that cost-minimizing production decisions are made by managers. Value will also be created if, on average, Ir helps to reduce inventory, cut material waste, and/or control labor overtime.

To address these concerns, we illustrate a method for analyzing the results of a data envelopment analysis (DEA) $[2,3,15]$ to evaluate a production process involving $\mathrm{TT}$. DEA is well suited to our analysis of Hardee's Positran technology, because it:

- can be used to address the problem of identifying Ir's role in complex production environments by modeling the production process;

- provides a mechanism to measure operational inefficiency in a generalized cost function, in which operational inefficiency is represented by a random variable, $\theta$;

- produces results that can be evaluated using new statistical hypothesis testing methods to determine if intermediate production performance improves in the presence of an $\mathrm{IT}$;

- opens up the possibility of creating an IT performance baseline, which can be used for comparison purposes in later periods, or to pinpoint the timing of the impact.

Carrying out hypothesis tests to identify "separation" in the performance frontiers of business units that operate under materially different conditions enables managers to identify more realistic and specific targets for their performance. A sample plot of a performance frontier is shown in Figure 1, for an arbitrary production correspondence involving one input and one output. The hypothesis of interest is whether the performance frontier for the units that have deployed an $I T$ to improve operational performance is farther northwest, on average, than for units that have not deployed the technology. 
OUTPUT

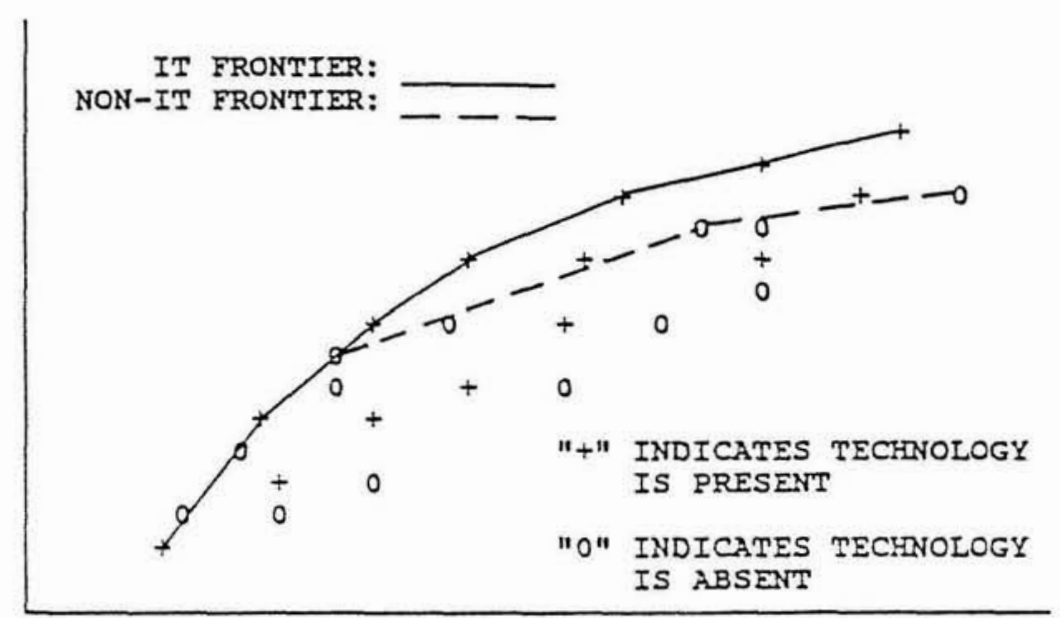

INPUT

Figure 1. The Separation of Nonparametric Frontiers: An Illustration

Although Figure 1 appears to show that the deployment of the IT leads to greater operating efficiency at higher production volumes, a more reliable answer would result by recasting this as a hypothesis and then carrying out a statistical test. Banker [5] developed a formal statistical test that enables such hypotheses regarding efficiency in nonparametric production frontiers to be more thoroughly examined. ${ }^{1}$ Restating the question of a "significant" difference in the IT and non- $\mathrm{TT}$ frontiers in statistical terms provides evidence for an impact. Thus, the primary methodological interest in this paper centers on the way the Hardee's materials cost function is evaluated to determine whether Positran tends, on average, to improve efficiency. We stress the words "on average" here, because of the possible presence of other factors in the production environment that could produce the same outcomes.

\section{Positran-Hardee's Inc.'s Cash Register and Order Coordination System}

\subsection{Hardee's Competitive Background: The Burger Segment of the Fast-Food Industry}

Hardee's Inc., a large fast-food retailing firm based in Rocky Mount, North Carolina, opened its first restaurant in 1961. While the majority of its operating units are located in the southeastern and midwestern United States, Hardee's Inc. competes at the national level with such well-known firms as McDonald's, Burger King, Wendy's, and Jack-in-the-Box. The firm's chairman, Jack Laugherty, reported that the firm's 
Table 1 Leading Burger Companies: Sales and Units

\begin{tabular}{lcc}
\hline leading burger firms & 1988 sales in \$MM (\# units) & 1987 sales in \$MM (\# units) \\
McDonald's & $\$ 16,100$ & $\$ 14,330$ \\
& $(10,513)$ & $(9,911)$ \\
Burger King & $\$ 5,400$ & $\$ 5,000$ \\
& $(5,793)$ & $(5,179)$ \\
Wendy's & $\$ 2,902$ & $\$ 2,870$ \\
& $(3,762)$ & $(3,816)$ \\
Hardee's & $\$ 2,733$ & $\$ 2,419$ \\
& $(3,100)$ & $(2959)$ \\
Jack-in-the-Box & $\$ 755$ & $\$ 655$ \\
& $(961)$ & $(897)$ \\
\hline
\end{tabular}

Source: Restaurants and Institutions, 99, 18 (July 10, 1989).

primary strategy is to "seek dominance in those regions where it is established and to expand only into contiguous regions" [29, p. D4].

Table 1 shows the relative sizes of these firms. Previously, Hardee's management viewed its most direct competitor as Burger King, which produces about twice as much revenue each year with slightly less than twice the number of units. McDonald's, as is evident from Table 1, is more than twice as large as Burger King and Hardee's combined. Among the three firms, Burger King and McDonald's tend to focus on serving a mostly blue-collar customer base. Hardee's, meanwhile, has increasingly targeted upscale fast-food customers. Wendy's competes for a similar customer segment, and, although Wendy's has just a slightly larger national market share, Hardee's management increasingly perceives Wendy's to be its primary competitor. In order to remain competitive with Wendy's and to maintain an image of slightly higher quality than McDonald's and Burger King, Hardee's experiments with a wide range of products, so that its menus continue to change to attract the interest of its upscale, health-conscious customers.

Hardee's is recognized in the burger segment as an innovator, and has been first to market in the past with popular menu items, such as breakfast biscuits and bacon burgers. As a result, hamburgers comprised only 45 percent of the firm's revenues by 1988 , down from about 65 percent in 1985. Although McDonald's pioneered breakfast fast food, Hardee's is widely credited with offering the broadest, most attractive breakfast menus in the industry. Laugherty comments: "It took the marketing clout of McDonald's to convince the American public that they could get a good breakfast in a hamburger establishment. We were able to capitalize on it with a bigger, better breakfast offering" [29, p. D4]. As a result, Hardee's tends to have a relatively larger portion of its sales derived from breakfast sales than its competitors, amounting to about $\$ 900$ million or 30 percent of total revenues in 1988 .

Hardee's 1983 decision to pilot test Positran, its cash-register and order-coordination automation, is indicative of management's interest in innovating to improve its overall service quality, despite the additional costs. The company has also made a strong commitment over the years to collecting data that can be used to track the 
performance of its operations (e.g., data related to pricing, product mix, location quality, restaurant layout, and materials use). Currently, each unit in the chain produces between $\$ 500,000$ and $\$ 1$ million per year in revenue. In addition to the one-time cost of purchasing a site and building the new unit, the primary ongoing costs of doing business are labor and materials. Enhanced control of materials usage was of considerable interest to Hardee's management, since the company's estimate of the value of wasted materials was about \$20 million, or on the order of 1 percent of sales.

Figure 2, adapted from Shaw [32], summarizes the primary issues that Hardee's faces in maintaining a competitive position in the burger segment of the fast-food industry. It also suggests the roles that $\mathrm{IT}$ can play in helping the firm to achieve competitive advantages.

\subsection{An Enhanced Cash-Register/Point-of-Sale Device}

The Positran technology deployed at Hardee's enhances a standard cash register so that it displays customer orders on a CRT Screen as they are entered into the cash register. This enables the customer to provide an initial check to make sure that the order was placed correctly. More importantly, though, Positran transmits the customer order to the food preparation area, where food preparers who were not involved in taking the order set it up and bag it. This replaced the old process, where the order taker called out the order to the food preparation area in a loud voice or via a microphone. There was some likelihood in the old process that the order recorded on the cash register slip would not completely match what was set up and bagged in the food preparation area. This would lead to a slowdown in order throughput, wasted materials, and customer dissatisfaction with the quality of Hardee's service.

Hardee's purchased the Positran technology from an outside vendor, SCAN-DATA Corp. of Morristown, Pennsylvania, at a cost of about $\$ 2,500$ per installation above the cost of a standard cash register system. Each investment in Positran is depreciated over a life of seven years by Hardee's accounting department, and Positran requires little maintenance besides that needed by the standard cash register. Hardee's management believed that this $\mathrm{IT}$ was likely to have beneficial effects on materials waste in restaurants where it was deployed. They recognized that the benefits might be maximized where Positran would help to offset the effects of other cost drivers. For example, materials waste was likely to increase when a unit operated an order counter and a drive-through window, since orders were flowing to the food preparation area from two different locations. This also had the potential to enable Hardee's to increase the diversity of its product line, without sacrificing efficient materials use. Another likely setting where materials waste would be large is high-volume restaurants, particularly at those times of the day when the order flow is large. On the other hand, in restaurants where alternative management control programs were in place (e.g., quality training and improvement programs, or a specially trained workflow coordinator), Positran was believed to reinforce changes that were already being obtained by these other means.

Positran was initially deployed by Hardee's in 1983 and 1984. At that time, the 


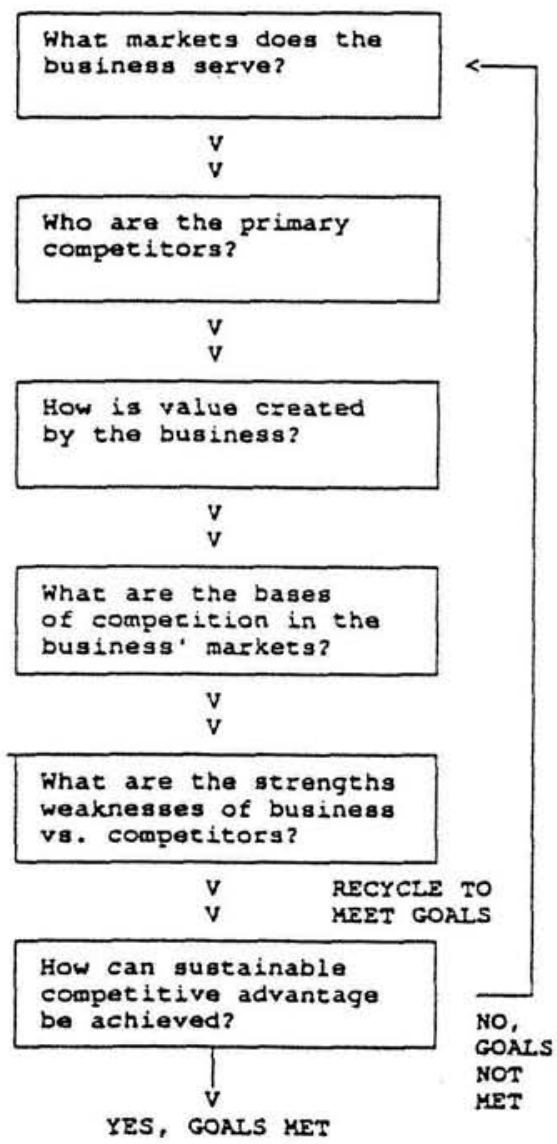

HARDEE'S ANSWERS

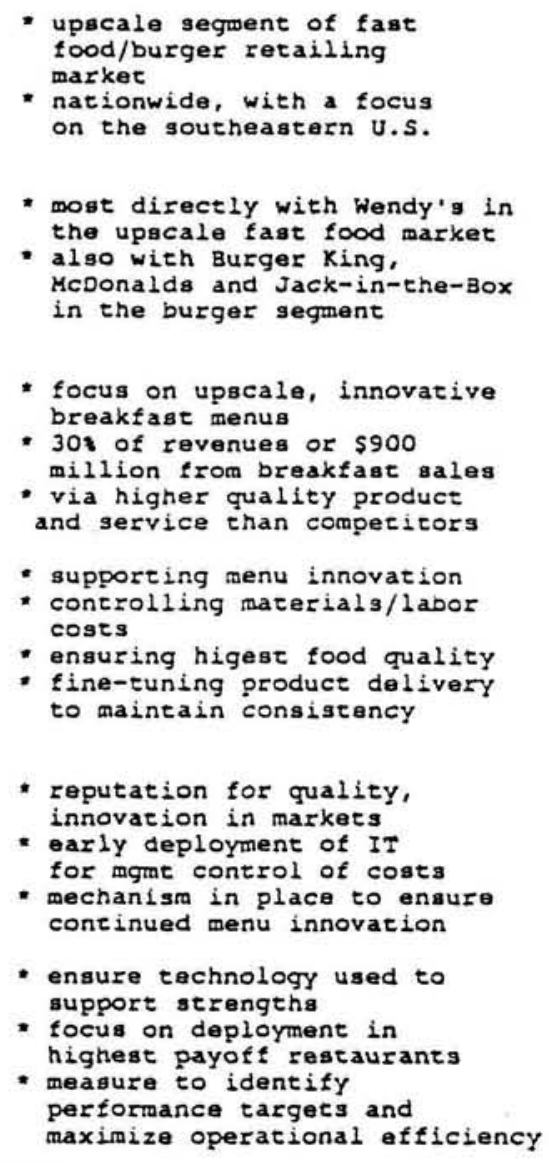

- upscale segment of fast market

nationwide, with a focus on the southeastern U.S.

most directly with Wendy'g in the upscale fast food market

also with Burger King,

McDonalds and Jack-in-the-Box

- focus on upscale, innovative breakfase menus

of reventes or

million from breakfast gales

via higher quality product

- supporting menu innovation controlling marerials/labor coses

ensuring higest food quality

fine-runing produce delivery

to maintain consistency

reputation for quality,

novarion in markers

for mgme control of costs

mechanism in placa to enaura upport strengths

highest payoff restauranes

performance targets and maximize operational efficiency

(Note: This figure is adapted from shaw (1990), p. 2.)

Figure 2. A Competitive Analysis of Hardee's Inc.

chain comprised some 2,600 units, and management was interested in identifying the value of deploying Positran more widely. But before proceeding with this program, more evidence was required about how Positran improved control of input material usage by reducing waste. Hardee's management also intended to work out the bugs and understand how Positran affected a restaurant's workflow and order throughput at peak order volume hours. From the outset, management's plan was to take a "rifle-shot" approach; they hoped to determine some rules of thumb for which kinds of units would derive the greatest value from the technology.

\subsection{Hardee's Positran Data Set and Input Materials Cost Function}

Hardee's management provided us with quarterly data on input material use and related descriptive information for 89 restaurants located in the state of North Carolina. All data collected reflect observations for individual restaurants for a representative 
quarter of the same year. Hardee's had implemented Positran at 48 of its units a minimum of three months (one quarter) or more prior to the period for which we obtained data. The remaining 41 restaurants did not have the new technology. Hardee's management indicated that this was a sufficient amount of time for the technology to be accepted and used appropriately in day-to-day operations by restaurant staff. ${ }^{2}$

The Hardee's Positran data set is shown in Table 2.

Comparing restaurant operations with and without Positran provides a natural and scientific test-bed for identifying its impacts on materials waste and productive efficiency. The restaurants that did not have Positran act as a control group. Hardee's management chose to deploy Positran to a random selection of locations in North Carolina, where the performance of the IT could be monitored closely by headquarters staff in Rocky Mount. As a result, we expect that no systematic selection biases were introduced in the data, and this was reinforced by our examination of the other descriptive variables mentioned above. Although we believe that the best test for the value of Positran would come from examining input material usage efficiency before and after Positran deployment, time-series data were not available. Cross-sectional analysis was an acceptable "next best" approach, especially in view of the time lag between the initial deployment of Positran and when our measurements occurred.

The primary materials cost driver was the overall volume of sales at a restaurant. Since Hardee's breakfast sales are relatively large in terms of total unit sales compared to its competitors, we collected data on sales volume in two categories: breakfast and other nonbreakfast menu sales. The additional data that were made available on individual restaurants included the presence of Positran, quarterly volume of restaurant sales, square feet of restaurant floor space, number of cashier positions and drive-up windows, number of new menu items, and staffing levels. However, a number of the restaurant descriptors generally were found to have little influence on input materials use.

In other situations, where a case could be made for the impact of a characteristic on materials usage efficiency, we observed relatively little variation. For example, all of the 89 restaurants in the sample had drive-through windows, which tend to increase the complexity of coordinating product delivery, and thus increase the potential for inefficiency. Another potential cost driver was the extent to which a unit was implementing new menu items; with more new menu items, more learning is required on the part of the staff, and input costs are likely to rise. We chose not to include this in the cost function, however, since new menu items were relatively uniform among the units for the quarter we studied.

Other factors examined included the quality of the local workforce, and managerial experience and training. Since we evaluated Hardee's units in North Carolina only, however, the quality of the workforce is fairly homogeneous across restaurants. Omitting this variable would have a greater impact on the quality of the results we might obtain if the initial deployment of Positran had not been limited to that single geographic area. 
Table 2 Hardee's Restaurant Data Set

\begin{tabular}{|c|c|c|c|c|}
\hline obs \# & $\begin{array}{l}\text { quarterly breakfast } \\
\text { sales }(\$ 000)\end{array}$ & $\begin{array}{l}\text { quarterly other } \\
\text { sales }(\$ 000)\end{array}$ & $\begin{array}{l}\text { quarterly materials } \\
\text { costs }(\$ 000)\end{array}$ & $\begin{array}{l}\text { Positran } \\
\text { present? }\end{array}$ \\
\hline 1 & 40.879 & 114.229 & 55.012 & $\mathrm{Y}$ \\
\hline 2 & 26.372 & 74.834 & 36.061 & N \\
\hline 3 & 32.698 & 153.780 & 68.158 & $\mathrm{~N}$ \\
\hline 4 & 49.764 & 111.459 & 57.400 & $\mathrm{Y}$ \\
\hline 5 & 35.500 & 173.784 & 77.488 & Y \\
\hline 6 & 52.672 & 108.448 & 56.710 & $\mathrm{~N}$ \\
\hline 7 & 33.034 & 85.111 & 42.776 & $\mathrm{~N}$ \\
\hline 8 & 42.402 & 177.471 & 74.347 & Y \\
\hline 9 & 50.002 & 66.303 & 44.564 & $\mathrm{~N}$ \\
\hline 10 & 29.746 & 83.038 & 43.215 & $\mathrm{~N}$ \\
\hline 11 & 42.123 & 132.799 & 61.042 & $\mathrm{~N}$ \\
\hline 12 & 54.245 & 149.541 & 70.261 & $\mathrm{Y}$ \\
\hline 13 & 32.327 & 74.681 & 40.477 & Y \\
\hline 14 & 39.601 & 137.539 & 59.068 & $\mathrm{Y}$ \\
\hline 15 & 44.648 & 247.207 & 99.091 & $\mathrm{Y}$ \\
\hline 16 & 42.704 & 128.989 & .59 .210 & $\mathrm{~N}$ \\
\hline 17 & 36.791 & 108.169 & 48.107 & $\mathrm{~N}$ \\
\hline 18 & 44.701 & 124.006 & 62.729 & $\mathrm{~N}$ \\
\hline 19 & 36.048 & 108.614 & 52.704 & Y \\
\hline 20 & 41.948 & 80.564 & 43.191 & $\mathrm{~N}$ \\
\hline 21 & 40.957 & 175.371 & 73.507 & Y \\
\hline 22 & 36.295 & 93.826 & 47.073 & $\mathrm{~N}$ \\
\hline 23 & 29.025 & 45.989 & 25.672 & $\mathrm{~N}$ \\
\hline 24 & 27.592 & 76.046 & 37.744 & $\mathrm{~N}$ \\
\hline 25 & 25.692 & 101.165 & 41.633 & $\mathrm{Y}$ \\
\hline 26 & 28.814 & 74.222 & 38.140 & $\mathrm{~N}$ \\
\hline 27 & 35.585 & 97.039 & 49.076 & $\mathrm{~N}$ \\
\hline 28 & 44.287 & 141.882 & 62.958 & N \\
\hline 29 & 25.060 & 83.220 & 40.563 & $\mathrm{~N}$ \\
\hline 30 & 38.375 & 98.028 & 48.745 & $\mathrm{Y}$ \\
\hline 31 & 41.779 & 111.336 & 54.098 & $\mathrm{~N}$ \\
\hline 32 & 40.977 & 75.968 & 39.650 & $\mathrm{~N}$ \\
\hline 33 & 25.974 & 105.448 & 45.546 & $\mathrm{~N}$ \\
\hline 34 & 26.943 & 90.568 & 44.452 & $\mathrm{Y}$ \\
\hline 35 & 26.179 & 68.609 & 37.378 & $\mathrm{~N}$ \\
\hline 36 & 49.953 & 154.970 & 69.526 & $\mathrm{Y}$ \\
\hline 37 & 38.789 & 66.301 & 37.322 & $Y$ \\
\hline 38 & 38.173 & 148.637 & 62.031 & $\hat{\mathrm{Y}}$ \\
\hline 39 & 41.322 & 102.247 & 52.617 & $\mathrm{~N}$ \\
\hline 40 & 35.195 & 83.948 & 40.745 & $\mathrm{~N}$ \\
\hline 41 & 26.470 & 63.822 & 32.534 & $N$ \\
\hline 42 & 26.454 & 133.664 & 67.782 & $\mathrm{Y}$ \\
\hline 43 & 32.026 & 98.565 & 47.038 & $\mathrm{Y}$ \\
\hline 44 & 34.817 & 61.282 & 34.040 & $N$ \\
\hline 45 & 26.470 & 88.795 & $=43.058$ & N \\
\hline
\end{tabular}


Table 2 Hardee's Restaurant Data Set (continued)

\begin{tabular}{|c|c|c|c|c|}
\hline obs \# & $\begin{array}{l}\text { quarterly breakfast } \\
\text { sales }(\$ 000)\end{array}$ & $\begin{array}{l}\text { quarterly other } \\
\text { sales }(\$ 000)\end{array}$ & $\begin{array}{l}\text { quarterly materials } \\
\text { costs }(\$ 000)\end{array}$ & $\begin{array}{l}\text { Positran } \\
\text { present? }\end{array}$ \\
\hline 46 & 26.454 & 47.745 & 27.464 & $N$ \\
\hline 47 & 33.263 & 91.503 & 45.293 & $N$ \\
\hline 48 & 44.359 & 126.443 & 60.998 & $N$ \\
\hline 49 & 21.926 & 81.385 & 36.738 & $\mathrm{~N}$ \\
\hline 50 & 41.560 & 100.484 & 48.195 & $Y$ \\
\hline 51 & 32.920 & 54.163 & 29.676 & $\mathrm{Y}$ \\
\hline 52 & 24.492 & 102.847 & 46.428 & $Y$ \\
\hline 53 & 40.643 & 160.200 & 68.124 & $Y$ \\
\hline 54 & 51.996 & 127.689 & 64.048 & $Y$ \\
\hline 55 & 29.726 & 96.914 & 42.395 & Y \\
\hline 56 & 22.714 & 165.672 & 69.124 & Y \\
\hline 57 & 35.915 & 126.002 & 54.022 & $N$ \\
\hline 58 & 38.125 & 112.743 & 44.552 & $N$ \\
\hline 59 & 38.610 & 100.485 & 48.029 & $N$ \\
\hline 60 & 28.154 & 105.645 & 46.039 & $N$ \\
\hline 61 & 43.625 & 135.839 & 69.378 & $Y$ \\
\hline 62 & 8.209 & 72.173 & 30.252 & $N$ \\
\hline 63 & 52.817 & 109.103 & 57.769 & $\mathrm{~N}$ \\
\hline 64 & 20.927 & 85.839 & 38.531 & $\mathrm{~N}$ \\
\hline 65 & 32.717 & 102.614 & 47.362 & $\mathrm{~N}$ \\
\hline 66 & 30.521 & 133.356 & 56.589 & $\mathrm{Y}$ \\
\hline 67 & 38.897 & 136.013 & 62.041 & $\mathrm{~N}$ \\
\hline 68 & 33.311 & 130.533 & 57.071 & $Y$ \\
\hline 69 & 50.523 & 89.599 & 45.909 & $\mathrm{~N}$ \\
\hline 70 & 45.455 & 137.071 & 75.766 & $Y$ \\
\hline 71 & 50.788 & 150.627 & 70.788 & $Y$ \\
\hline 72 & 26.913 & 77.553 & 37.021 & $\mathrm{Y}$ \\
\hline 73 & 39.584 & 145.039 & 61.972 & $N$ \\
\hline 74 & 31.812 & 72.658 & 37.227 & $Y$ \\
\hline 75 & 41.050 & 156.179 & 67.455 & $Y$ \\
\hline 76 & 37.807 & 102.271 & 48.204 & $Y$ \\
\hline 77 & 28.108 & 62.938 & 32.185 & $N$ \\
\hline 78 & 41.809 & 142.510 & 63.925 & $Y$ \\
\hline 79 & 40.245 & 113.638 & 54.989 & $Y$ \\
\hline 80 & 21.877 & 78.337 & 38.419 & $Y$ \\
\hline 81 & 30.393 & 89.254 & 41.408 & $Y$ \\
\hline 82 & 59.308 & 170.017 & 79.473 & $Y$ \\
\hline 83 & 37388 & 83.689 & 42.060 & $Y$ \\
\hline 84 & 25.594 & 85.220 & 42.096 & $Y$ \\
\hline 85 & 27.057 & 80.505 & 39.157 & $Y$ \\
\hline 86 & 32.345 & 97.194 & 44.006 & $\mathrm{Y}$ \\
\hline 87 & 29.885 & 95.073 & 43.184 & $Y$ \\
\hline 88 & 48.948 & 158.843 & 68.285 & $\mathrm{Y}$ \\
\hline 89 & 28.205 & 99.894 & 44.592 & $\mathrm{Y}$ \\
\hline
\end{tabular}




\section{A Model that Captures Positran's Effects on Input Inefficiency}

\subsection{A Generalized Cost Function Incorporating Random Inefficiency}

As a basis for an illustration of our ideas and measurement of the impacts of Positran on aggregate materials cost efficiency, we employ a simplified cost function. This cost function maps a set of outputs into input use. This relation includes a random inefficiency component, which represents the effects of the way an operation is managed, the impact of $\mathrm{Ir}$ on the operation, and other variables that cannot be measured directly. The generalized cost function (which we will shortly specify for Hardee's) is written as follows:

$$
c=f(Y) * \theta
$$

where

$$
\begin{aligned}
& c=\text { observed use of input materials; } \\
& Y=\text { vector of outputs in production process; } \\
& \theta=\text { a random variable for inefficiency, whose values range between } 1 \\
& \text { and infinity. }
\end{aligned}
$$

In this model the variable, $\theta$, is assumed to be exponentially distributed with $E[\theta]=(1+1 / \delta)$, and the probability density function, $g(\bullet)$, given by $g(\theta \mid \delta)=$ $\delta e^{-\delta(\theta-1)}$, for $\theta \geq 1$, and 0 otherwise. $^{3}$

We further assume that the function $f(Y)$ is monotone increasing and convex in the variables described. These assumptions place minimal structure on the form of the function, and enable the application of our method to a wide range of production environments influenced by $\pi$. By including the random variable for inefficiency, $\theta$, the method also directly addresses concerns that have been raised about the utilization of nonparametric production frontiers in the econometrics literature (for example, see Schmidt [33]) in situations where hypothesis testing is necessary.

Our formulation of the cost function implies that variables omitted from the function $f(Y)$ are reflected in the random variable, $\theta$. If the presence of $\mathrm{rT}$ causes input use to decline, then it will cause the distribution of inefficiency scores across the restaurants to shift to the left. That is, while it is not certain that efficiencies will decline in all cases in the presence of $\mathrm{Ir}$ (because other variables may counteract the effect of $\mathrm{IT}$ ), lower inefficiency values will become more likely. The main challenge is to detect such a shift and support the argument that reduction in waste is attributable to IT.

\subsection{DEA Model and Analytic Approach}

We next present a model based on this approach to gauge the impact of Positran on input use in Hardee's restaurants. Rewriting the generalized cost function presented above to incorporate the relevant variables, we have the following.

$$
c=f\left(Y_{\text {BRK_SALES }}, y_{\text {OTHER_SALES })} \theta\right.
$$


where the variables $y_{\text {BRX_SALES }}$ and $y_{\text {OTHER_SALES }}$ represent quarterly breakfast and nonbreakfast sales volumes, respectively. The distribution of the random inefficiency variable $\theta$ is affected by the presence of Positran, among other factors, which we omit to focus our analysis on $\mathrm{IT}$. In this case, the variable $c$ is the actual quarterly materials cost.

Our measurement approach makes use of all the information present in Hardee's aggregate materials input cost function via a two-step analysis. The first step is to run a deterministic DEA model (see [3]) to obtain inefficiency scores for input resource use. The mathematical program that structures this analysis is based on a DEA model incorporating categorical variables, as discussed in Banker and Morey [10]. Using the model shown below enables us to estimate the efficiency $h_{0}$ (reciprocal of the inefficiency $\theta_{0}$ ) for any specific restaurant distinguished here by the subscript 0 .

$$
\text { Minimize } h_{0}
$$

subject to

(2)

$$
\sum_{j=1}^{89} y_{\text {OTHER_SALES, } j} \lambda_{j} \geq y_{\text {OTHER_SALES, } 0}
$$

$$
\sum_{j=1}^{89} y_{\text {BRR_SALES, } j} \lambda_{j} \geq y_{\text {BRK_SALES, } 0}
$$

$$
\sum_{j=1}^{89} w_{j} \lambda_{j} \geq w_{j}
$$

$$
\sum_{j=1}^{89} c_{j} \lambda_{j} \leq h_{0} c_{0}
$$

$$
\sum_{j=1}^{89} \lambda_{j}=1
$$

$$
c_{j}, \lambda_{j} \geq 0 \quad(j=1,2, \ldots, 89)
$$

This program models one input, aggregate materials cost (c), and two outputs $(y)$, breakfast and nonbreakfast sales. The reciprocal of the solution $h_{0}{ }^{\circ}$ to the program for restaurant 0 provides a measure for input use inefficiency $\left(\theta^{*}=1 / h_{0}{ }^{\circ}\right)$. Also obtained by solving the math program is a set of $\lambda_{j}{ }^{*}$ 's identifying the restaurants to which the restaurant being evaluated is compared. The variable $w$ codes the presence $(w=0)$ or the absence $(w=1)$ of Positran at any of the 89 : restaurants identified by the subscript $j$.

The first two constraints (represented by equations 2 and 3 ) in the math program ensure that the output levels of inefficient restaurants are compared to the output levels of a convex combination of restaurants at least as large. The next constraint (4) ensures that restaurants without Positran only are compared to restaurants that also have not 
deployed Positran. On the other hand, restaurants that have deployed Positran may be compared to both Positran and non-Positran restaurants. This formulation recognizes that it will be harder to achieve efficient performance in the absence of Positran, because the conditions of production are more constrained. The following constraint (5) maintains the envelopment conditions for the input (i.e., that all observed input combinations lie on or within the production space defined by the production frontier) and provides a means to enable the analyst to interpret the $h_{0}{ }^{*}$ 's as input use efficiency scores. The next constraint (6) implements convexity in the production correspondence. The last constraint (7) ensures that all values of the production correspondence convexity weights, $\lambda_{j}$, and the materials costs, $c_{j}$, be greater than or equal to zero.

Once the DEA scores, $h_{0}{ }^{*}$, have been obtained by iteratively running 89 DEA programs, the second step is to classify restaurants into groups with similar characteristics and test hypotheses about the differential effects of Positran on materials use efficiency. We provide a more complete discussion of the hypothesis tests in the following section.

\section{Hypothesis Tests and Results}

\subsection{Hypothesis Tests for the Operational Efficiency Effects of Positran}

For the purpose of testing the hypothesis that the presence of Positran technology improves input productivity at a Hardee's restaurant, let $j$ represent a restaurant in the overall data set. The set $J$ of restaurants consists of two subsets, $A_{1}$ and $A_{2}$. Restaurant $j$ is an element of the subset $A_{1}$ if management has not installed Positran on its premises, and an element of $A_{2}$ if Positran has been installed. We will denote the inefficiency of restaurant $j$ in group $A_{i}$ by $\theta_{j}^{i}$ to distinguish it, and allow for the possibility that the probability distribution of $\theta^{1}$, differs from that of $\theta^{2}$. Let the distribution of $\theta^{1}$ be exponential with mean $1+\left(1 / \delta_{1}\right)$, and $\theta^{2}$ be exponential with mean $1+\left(1 / \delta_{2}\right)$. Thus, the simplest null hypothesis is that Positran deployment does not influence the random inefficiency scores:

$$
H_{01}: \delta_{1}=\delta_{2} \text {. }
$$

The alternate hypothesis is:

$$
H_{01}: \delta_{1}<\delta_{2} \text {, }
$$

i.e., that Positran deployment leads to a reduction in input inefficiency on average for this data set.

This kind of hypothesis test is of general interest whenever management wishes to determine whether the differential efficiency of two groups of business units can be attributed in some way to factors within or beyond the control of management. Chames, Cooper, and Rhodes [15], for example, compared school performance with and without an accountability program. Banker, Datar, and Kemerer [6], using software develop- 
* of observations

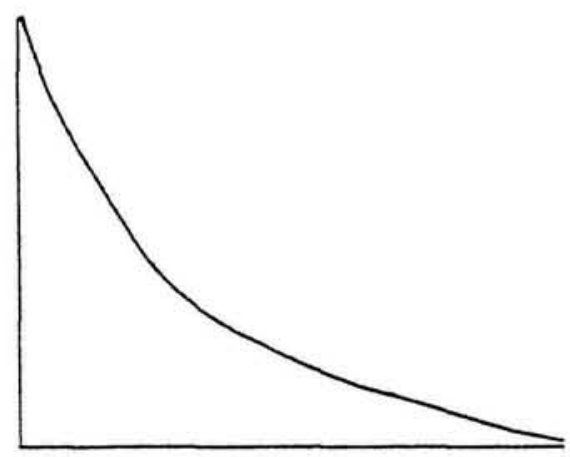

0.00

1.00

Efficiency Score Deviations

EXPONENTTAL

DISTRIBUTION $\neq$ of

Observations

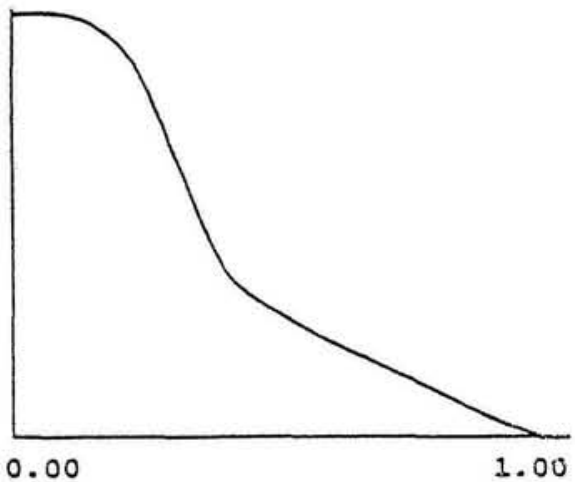

Efficiency Score Deviations

EALF-NORMAL

DISTRIBUTION

Note: The eftleiency score deviation is given by 1 - $h$, for zestauzant 0 .

Figure 3. Exponential and Half-Normal Distributions for Efficiency Score Deviations

ment projects as their unit of analysis, attempted to correlate software maintenance labor productivity with the use of a structured development methodology.

Generally speaking, the probability of a small amount of inefficiency in production is high, while the probability of highly inefficient operations is low. An exponential distribution for the DEA inefficiency scores, $\theta$, is appropriate whenever the analyst believes that most of the observations are close to the frontier. If fewer observations are expected to be close to the frontier, then it is appropriate to use a half-normal distribution to represent $\theta$ 's probability distribution. Both distributions capture the idea that the likelihood of inefficient observations decreases for larger inefficiency levels (see Figure 3). To illustrate, we will examine results related to both distribution assumptions and discuss how they can be interpreted.

After solving the DEA models discussed above to determine the set of inefficiency scores, we carried out hypothesis tests to determine whether the means of the Positran and non-Positran inefficiency score probability distributions were actually different. The relevant test statistic assuming an exponential distribution of inefficiency scores has been suggested by Banker [5]. We assume a large sample of DEA inefficiency scores, $\theta_{j}$. Under the null hypothesis, we perform a statistical test using the following statistic:

$$
\frac{\sum_{j \in A_{2}}\left(\theta_{j}^{2}-1\right) / a_{1}}{\sum_{j \in A_{1}}\left(\theta_{j}^{1}-1\right) / a_{2}}
$$


This statistic asymptotically follows the $F$-distribution with $\left(2 a_{2}, 2 a_{1}\right)$ degrees of freedom, where $a_{i}, i=1,2$ is the number of observations in the sets $A_{i}$.

Assuming a half-normal distribution of inefficiency scores requires the following test statistic instead:

$$
\frac{\sum_{j \in A_{2}}\left(\theta_{j}^{2}-1\right)^{2} / a_{1}}{\sum_{j \in A_{1}}\left(\theta_{j}^{1}-1\right)^{2} / a_{2}}
$$

This statistic also follows an $F$-distribution, however, with $\left(a_{2}, a_{1}\right)$ degrees of freedom. Banker [5] contains additional details for this test as well.

A second set of hypotheses was also of interest to Hardee's management. This involved attempting to identify whether Positran has a different impact on restaurants with a high percentage of breakfast sales versus those that do not. We further divided the subsets $A_{1}$ and $A_{2}$ into $A_{1, \text { HIGH }}$ and $A_{1, \text { LOW }}$, and $A_{2, \mathrm{HIH}}$ and $A_{2, \text { LOW, }}$ respectively. The subscript HIGH indicates a high percentage of breakfast sales relative to the average, and the subscript Low indicates a lower than average percentage of breakfast sales. ${ }^{4}$

The rationale for the significant impact of Positran in restaurants with a higher percentage of breakfast sales is that the breakfast menus are more complicated than those offered during nonbreakfast hours. This provides additional opportunities for mismatching orders, and Positran appears to provide management with some additional control over the production process.

The relevant null hypothesis here is that the presence of Positran does not lead to observed productivity differences in Hardee's restaurants with a relatively larger percentage of breakfast sales than the mean across all restaurants in the data set:

$$
H_{02}: \delta_{1, \text { HIGH }}=\delta_{2 \text { HIGH }}
$$

Since Hardee's management believed that Positran would pay off to a greater extent in high-breakfast-percentage restaurants, where menu complexity increases the likelihood of materials waste, it was expected that our tests would show that $H_{02}$ was rejected in favor of:

$$
H_{0_{2}}{ }^{\prime}: \delta_{1, \mathrm{HIGH}}<\delta_{2 \mathrm{HIH}}
$$

As we indicated above, Hardee's management did not expect Positran to be as influential in improving productivity in low-breakfast-percentage sales restaurants. This yielded a third hypothesis:

$$
H_{03}: \lambda_{1, \mathrm{WW}}=\lambda_{2 \text { LOW }}
$$

To test the null hypotheses, $H_{02}$ and $H_{03}$, assuming an exponential distribution of inefficiency scores, a similar test statistic is utilized. However, it must be adjusted to reflect the number of elements in the smaller subsets (e.g., $A_{1, \text { HIGH }}$ contains $a_{1 \text { HIGH }}$ restaurants, $A_{2 \text { HIGH }}$ contains $a_{2 \text { HIGH }}$ restaurants, and so on). So; for $H_{02}$, we have: 


$$
\sum_{j \in \frac{A_{2, \mathrm{HGH}}}{\sum_{A_{1, \text { HGH }}}\left(\theta_{j}^{1 . \mathrm{HIH}}-1\right)^{r} / a_{2, \mathrm{HIGH}}}}
$$

This also follows the $F$-distribution with ( $\left.2 a_{2 \mathrm{HGH}}, 2 a_{1, \mathrm{HIHH}}\right)$ degrees of freedom, where $a_{1, \text { HIG }}$ and $a_{2 \text { HIG }}$ are the number of observations in the sets $A_{1, \text { HIG }}$ and $A_{2, \mathrm{HIGH}}$. (The statistical test for $H_{03}$ is identical, requiring the substitution of Low whenever HIGH appears in the test statistic above.) Testing the null hypotheses under the assumption of a half-normal distribution of $\theta$ requires additional modification of the test statistic, the number of observations in the data set, and the degrees of freedom.

This general approach can also be used to examine the extent to which the physical size, number of cashier positions, and presence of a drive-up window in a restaurant affect input use inefficiency. Management will want to use as much information as it has available to enhance the usefulness of the results for managers.

\subsection{Results of Hypothesis Tests}

Table 3 summarizes the outcomes of the hypothesis tests of the DEA results. (For a fuller presentation of the DEA results, and a more detailed methodological treatment of the estimation issues, see Banker and Morey [10].) $H_{01}: \delta_{1}=\delta_{2}$, tested under the assumptions of an exponential and half-normal for the inefficiency scores, could not be rejected at the 10 percent significance level (exponential case: $F$-statistic $=1.214$ with $(82,96)$ degrees of freedom; half-normal case: $F$-statistic $=1.265$ with $(41,48)$ degrees of freedom). Although we observed somewhat different mean inefficiency scores, they proved not to be statistically different for our sample of 48 restaurants with and 41 without Positran. The mean inefficiency score for the entire data set of 89 restaurants was 1.057; this implies that material costs could be reduced by 5.7 percent if all restaurants exhibited 100 percent efficient operation.

The results of the test for the null hypothesis, $H_{02}: \delta_{1, \mathrm{HCH}}=\delta_{2 \mathrm{HGH}}$, were more interesting to Hardee's management. When we focused only on the 44 higher-percentage-breakfast-sales restaurants, the mean of the inefficiency scores appeared to be significantly larger for non-Positran, as compared to Positran restaurants. Under the assumption of a half-normal distribution of inefficiency scores, the null hypothesis was rejected at an 8.7 percent significance level $(F$-statistic $=1.89$ with $(27,17)$ degrees of freedom). However, when an exponential distribution is assumed for the inefficiency scores instead, this result no longer was evident $(F$-statistic $=1.199$ with $(54,34)$ degrees of freedom).

Our test of the null hypothesis, $H_{03}: \delta_{110 \mathrm{w}}=\delta_{210 \mathrm{w}}$, that the presence or absence of Positran has little influence on productivity in low-percentage-breakfast sales restaurants, confirmed management's intuition. The nuil hypothesis could not be rejected for the 44 low-percentage-breakfast sales stores for an exponential $(F$-statistic $=1.128$ with $(28,60)$ degrees of freedom $)$ or a half-normal $(F$-statistic $=1.00$ with $(14,30)$ degrees of freedom) distribution of inefficiency scores. 
Table 3 Results of Six Hypothesis Tests

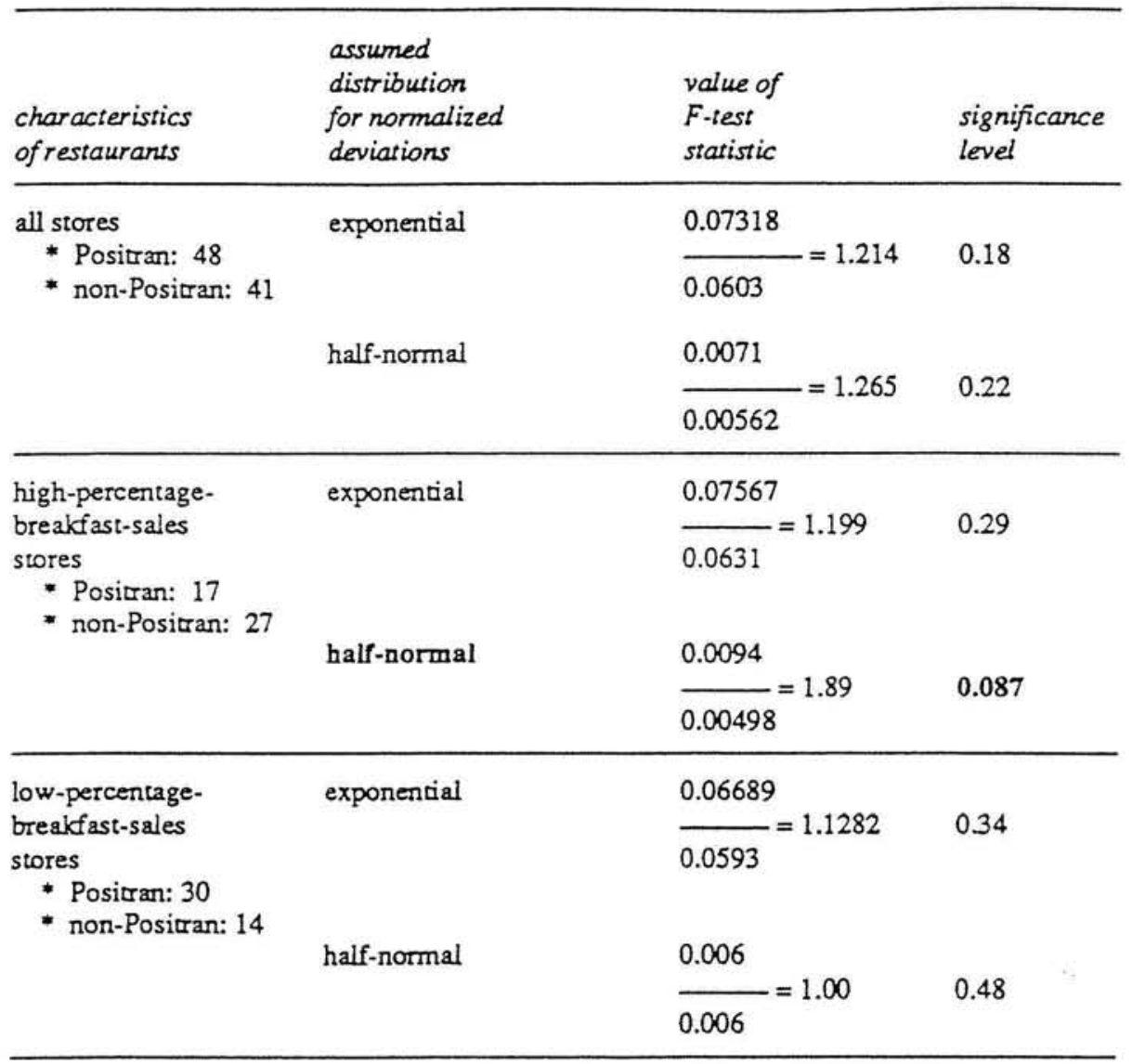

\subsection{Managerial Significance of Results}

Since the Positran device costs about $\$ 2,500$ over the cost of a standard cash register, and Hardee's had some 2,600 outlets at the time of the study, at risk was an investment of $\$ 6.5$ million in rr. Of particular interest to Hardee's management was the ability to develop a Positran deployment policy that would lead to maximal business value.

Table 2 indicates that quarterly materials cost averaged $\$ 51,161$ and ranged between $\$ 25,652$ and $\$ 77,488$. Since the difference in average inefficiency between the restaurants without and with Positran was about 7.32 percent -6.03 percent $=1.29$ percent, we estimated the annual value of Positran in reducing input waste to be about $\$ 51,161 \times 1.29$ percent $\times 4$ quarters $=\$ 2,660$ for an ayerage restaurant. Clearly, the deployment of the Positran technology to an appropriate location would enable an almost immediate payback of the initial investment and provide the basis for additional future savings. Extrapolating from our data set, there were about 1,000 (40 percent) of the firm's restaurants that might have been classified as high-percentage-breakfast sales outlets, offering the firm an opportunity to reduce input resource costs by nearly 
$\$ 2.7$ million per annum. Since the firm's strategy involved increasing the proportion and volume of profitable breakfast sales in many of its units, system-wide deployment had the potential to save the firm even more money.

Results such as these were useful to Hardee's management in planning the investment and installation of Positran in its company-owned outlets and in advising its franchisees about the business value of Positran. Most large fast-food restaurant chains are able to muster significant expertise to identify revenue-maximizing locations. Often the operator of a chain retains ownership of the locations it believes will be the most profitable. In the case of Hardee's, offering to install Positran in franchised locations can provide the franchisees additional profit opportunities through cost control. This serves to maintain the value of existing franchises and also gives Hardee's some leverage to attract new investors as franchisees. Still, our results highlight the fact that Positran makes a difference, but only in restaurants with selected characteristics. Thus, management must exercise special care in selecting where to deploy the Positran technology so as to maximize its contribution to the operational performance of the firm.

\section{Concluding Remarks}

POSTIRAN IS REPRESENTATIVE OF AN INCREASING NUMBER of restaurant information technologies that deliver a range of services at the point at which retail sales occur. At the time that Positran was initially deployed, Hardee's was investigating the roles that information technologies might play in changing its business. Based on the firm's success with Positran and other ITS it has deployed, Hardee's commitment to IT has grown significantly over time. As a result, Positran is now a part of an integrated point-of-sale system that is reputed to be the largest and most sophisticated in the industry, linking the firm's restaurants nationwide. According to a report in the New York Times.

The system collects data from every transaction made at every Hardee's restaurant, including the product sold, the price, the time of sale and whether it was eat-in or take-out. ... the system enables [senior executives] to monitor sales throughout the chain to within the last 15 minutes. Using this information, Hardee's can fine-tune its operations in ways that can make it millions of dollars. [29, p. D4]

For example, Hardee's was recently able to utilize data captured by this system concerning the purchase of less popular menu items, such as turkey sandwiches and mushroom and Swiss cheeseburgers, that were discontinued in the early 1980 s due to lackluster sales. Analysis of point-of-sale data showed that customers simultaneously purchased one or more higher-margin menu items (such as french fries and soda), and that discontinuing the less popular items caused Hardee's to lose these customers to competitors. This led management to reinstate the discontinued items on Hardee's menus $[29$, p. D4]. 
Hardee's has positioned itself so that a technology that continues to provide important operational productivity gains is no longer just a "stand-alone" capability that any of its competitors would be able to purchase off the shelf from a third-party vendor and readily imitate. Instead, Positran offered Hardee's the basis of an infrastructure at the point of sale that is expandable to capture a range of other data that will enable management to make further improvements to the firm's operating efficiency and marketing effectiveness.

\subsection{Summary of Results}

To summarize, our primary result is that Positran appears to have reduced materials waste in the high-percentage-breakfast sales restaurants where it was deployed. The method we used to obtain this result relies on statistical tests that utilize information about the inefficiency scores of all units in the analysis. We recognized explicitly that input use at Hardee's restaurants can be modeled using a nonparametric frontier, thus requiring minimum assumptions about the form of the production correspondence. This also enabled us to use a standard DEA model to solve for the inefficiency results. Our primary methodological innovation is that random inefficiency results obtained from the DEA model can be used for hypothesis testing. We focused on detecting whether the means of the distributions of inefficiency scores vary across restaurants with different characteristics. When they vary with the presence of an IT variable-in this instance, Positran - we can make a case that the technology influences input use.

Examining the deployment of Positran at Hardee's is insightful, because it allows us to show how to model how IT enters a production process, and probabilistically affects input productivity. We also have shown how to detect such impacts by testing a set of simple hypotheses, utilizing formal statistical tests to examine the influence of varied assumptions that match a reasonable analyst's intuition. Our approach utilizes methods based on production economics, mathematical programming, and statistics, yet it can be applied by analysts who have access to desktop workstations. No doubt, it will continue to be a challenge to collect large and rich samples of data, and to identify instances where a simulated $I T$ value experiment can be carried out with a control group and a test group. Nevertheless, we expect that managers who endeavor to carry out this kind of analysis stand to gain a deeper understanding of the critical environmental factors that lead to differential returns on $\mathrm{IT}$ investments in complex managerial environments.

\subsection{Limitations and Future Research Directions}

Although the importance of the potential contributions of $I T$ in most firms today is unquestioned, the ability of senior management to achieve a positive return on $\mathrm{Ir}$ investments continues to be a topic of heated debate $[19,24]$. As a result, better measurement methods for $\mathrm{IT}$ value are critical for senior managements responsible for large, discretionary information systems budgets. Lucas [28] has suggested that substantiating the business value of an $I T$ requires showing two things: 
(1) that a performance gain is correlated with the deployment of an IT, and

(2) that a performance gain follows from the deployment of the IT.

Our results suggest the usefulness of measuring $I T$ impacts in the segments of the value chain in which they occur.

The use of $\mathrm{IT}$ for improving operational control places added emphasis on identifying investment and performance evaluation methods, which realistically recognize the variety of factors that can produce results similar to those deriving from the deployment of $\mathrm{Tr}$. These include productivity incentive programs, management training, upgraded physical facilities, and so on. Compounding the problem of Ir performance assessment is the reality that identical ITS may be utilized in rather different ways in different units of a firm, and that other aspects of managerial control may create the same effects as $\mathrm{TT}$.

As a result, one concern we had in this research was the extent to which management practice in Hardee's restaurants varied from one unit to another. Discussions with management suggested that the primary differences are discernible in units of different size. For example, restaurants with a larger floor area and sales volume normally have managers on-site who act as workflow coordinators and trouble-shooters. In smaller restaurants, managers are more likely to be involved in the work itself, at the cash register, in food preparation, or maintaining the facilities. Thus, any influences from different management practices in restaurants of different size are likely to be captured by the sales volume variable. However, we were not able to obtain results to bear out these assertions.

A natural next step is to extend the present analysis using a time series of quarterly observations on Hardee's materials costs and unit sales. This would support hypothesis tests about how rapidly Positran produced the desired effects in high-breakfast-sales units. It would also allow us to explore in more depth the extent to which a workflow coordinator and Positran provide similar benefits. Given the data available to us, the strongest test we could perform in the present research was a cross-sectional one.

Even recognizing Lucas's requirements stated above, the Hardee's Positran data set is an uncommonly rich one for is research, since management had installed Positran in roughly half of the sites just prior to the test period. A related issue that could be explored in an extension of this work is the set of conditions that push a unit down the Positran leaming curve the fastest. This would enable Hardee's management to take steps to refine other aspects of the workflow in its units at the same time Positran is deployed. Finally, although we have obtained results indicating Positran's value with respect to materials use, there may be labor saving and other dimensions of cost reductions that could be identified by employing alternative models including different outputs.

\section{ACKNOWLEDGMENTS}

We wish to thank Mr. John C. Wilson, formerly senior vice president and chief financial officer of Hardee's Food Systems, Rocky Mount, North Carolina, for providing access to the data and restaurants discussed in this study. We acknowledge 
Eric Clemons, Peter Sassone, Peter Weill, and the anonymous referees of this paper for their helpful comments. An earlier version of this work was presented at the First Workshop in Information Systems and Economics (WISE), MIT, December 1989, and also appeared in the Proceedings of the Twenty-Third Annual Hawaii International Conference on Systems Sciences, January 1990.

\section{NOTES}

* An earlier version of this paper was published in the Proceedings of the Twenty-Third Hawaii International Conference on System Sciences. IEEE Computer Society Press, 1990.

1. The reader should note that we are not employing another relatively newer approach called "stochastic DEA." Stochastic DEA incorporates the possibility of a two-sided error term-inefficiency and random error-directly into the mathematical program that is run to obtain the efficiency scores. For additional details, see Banker [4].

2. Of course, our study requires this to be the case. Otherwise, in view of the well-documented short-term decreases in productivity and performance that are observed when new technologies are introduced within a firm [23], it is possible that non-Positran restaurants might exhibit less resource waste and thus higher levels of operational efficiency.

3. Since inefficiency scores vary between 1 and infinity, we adjust the mean of the standard exponential distribution $(1 / \delta)$ when the random variable varies between 0 and infinity, by adding 1 to it.

4. The median Hardee's restaurant in the data set had a breakfast sales percentage of 23.3 percent, with a minimum of 4 percent and a maximum of 43 percent. The 25 th percentile was 21.83 percent, and the 75 th percentile about 28.13 percent. The mean percentage of breakfast sales was 24.82 percent across the 89 restaurants.

\section{REFERENCES}

1. Alpar, A., and Kim, M. Approaches to the measurement of information technology value. Journal of Management Information Systems, this issue, 55-69.

2. Banker, R. D.; Chames, A.; and Cooper, W. W. Some models for estimating technical and scale inefficiencies in data envelopment analysis. Management Science, 30, 9 (Septembet 1984), 1078-1092.

3. Banker, R. D. Productivity measurement and management control. In The Management of Productivity and Technology in Manufacturing, P. Kleindorfer, ed. New York: Plenum Publishing. 1985.

4. Banker, R. D. Stochastic data envelopment analysis. Working Paper, School of Urban and Public Affairs, Camegie-Mellon University (April 1988).

5. Banker, R. D. Maximum likelihood, consistency and data envelopment analysis: a statistical foundation. Working Paper, School of Urban and Public Affairs, Carnegie-Mellon University (April 1988).

6. Banker, R. D.; Datar, S. M.; and Kemerer, C. F. Software development productivity messurement. In Proceedings of the Eighth International Confer ence on Information Systems, Pittsburgh, Pennsylvania (December 1987).

7. Banker, R. D., and Kauffman, R. J. Strategic contributions of information technology: an empirical study of ATM networks. In Proceedings of the Ninsh International Conference on Information Systems, Minneapolis, Minnesota (December 1988).

8. Banker, R. D., and Kauffman, R. J. A scientific approach to the measurement of $m$ business value-Parr I: A manager's guide to 'business value linkage' impact analysis. Working Paper \#194, Center for Research on Information Systems, Stern School of Business, New York University (September 1988).

9. Banker, R. D., and Kauffman, R. J. A scientific approach to the measurement of $I T$ business value-Part II: A case study of electronic banking operations at Meridian Bancorp. 
Working Paper \#195, Center for Research on Information Systems, Stem School of Business, New York University (September 1988).

10. Banker, R. D., and Morey, R. C. Evaluating hypotheses about production frontier shifts. Working Paper, College of Business Administration, University of Cincinnati (January 1990).

11. Banker, R. D., and Kauffman, R. J. An empirical assessment of computer aided software engineering (CASE) technology: a study of productivity, reuse and functionality. Working Paper, Center for Research on Information Systems, Stern School of Business, New York University (May 1990).

12. Benham, H. C. A measure of information system impact. Working Paper, Division of Economics, University of Oklahoma (October 1988).

13. Carlson, W. M., and McNurlin, B. C. Measuring the value of information systems. I/S Analyzer Special Report, United Communications Group, Bethesda, MD (1989).

14. Cash, J. I., Jr.; McFarlan, F. W.; and McKenney, J. L. Corporate Information Systems Management-The Issues Facing Senior Erecutives, second edition. Homewood, II: Irwin, 1988.

15. Chames, A.; Cooper, W. W.; and Rhodes. E. Measuring the efficiency of decision making units. European Journal of Operations Research, 2, 6 (1978).

16. Chismar, W. C., and Kriebel, C. H. A method for assessing the economic impact of information systems technology on organizations. In Proceedings of the Sizth International Conference on Information Systems, Indianapolis, Indiana (December 1985).

17. Clemons, E. K., and Row, M. McKesson Drug Company's Economost. Journal of Management Information Systems (Summer 1988), 36-50.

18. Clemons, E. K. MAC-Philadelphia Nacional Bank's strategic venture in shared ATM networks. Journal of Management Information Systems, 7, 1 (Summer 1990).

19. Clemons, E. K. and Weber, B. Making the information technology investment decision: a principled approach. In Proceedings of the Twenty-Third Hawaii International Conference on Systems Science, 4 (January 1990), 147-156.

20. Crowston, K., and Treacy, M. E. Assessing the impact of information technology on enterprise level performance. In Proceedings of the Seventh International Conference on Information Systems, San Diego, California (December 1986), 299-310.

21. Dos Santos, B. Justifying investments in new information technologies. Working Paper, Krannert School of Business, Purdue University (December 1989).

22. Harris, S. E., and Katz, J. L. Profitability and information technology capital intensity in the insurance industry. In Proceedings of the Twenty-First Annual Hawaii International Conference on System Sciences, 4 (January 1988), 124-130.

23. Hayes, R. C., and Wheelwright, S. C. Restoring a Competitive Edge: Competing Through Manufacturing. New York: John Wiley, 1984.

24. Kauffman, R. J., and Kriebel, C. H. Modeling and measuring the business value of information technology. In Measuring the Business Value of Information Technologies, edited by ICIT Research Study Team \#2. Washington, DC: ICIT Press, 1988.

25. Kauffmar, R. J., and Kriebel, C. H. Identifying business value linkages for production processes involving information technology. In Advances in Working Capital Management, Vol. 2. Y. H. Kim and V. Srinavasan, eds. New Haven, CT: JAI Press, 1989.

26. Kauffman, R. J., and Weill, P. An evaluative framework for research on the performance effects of information technology. In Proceedings of the Tenth International Conference on Information Systems, Boston, MA (December 1989).

27. Loveman, G. An assessment of the productivity impact of information technologies. Working Paper, Management in the 1990s. Sloan School, MIT (1988).

28. Lucas, H. C., Jr. Methodological issues in information systems survey research. Working Paper \#206, Center for Research on Information Systems, Stern School of Business, New York University (May 1989).

29. McGill, D. C. At Hardee's, fast foods and trends. New York Times (January 8, 1988), D1-D4.

30. Parker, M. J., and Benson, R. J. Information Economics: Linking Business Performance to Information Technology. Englewood Cliffs, NJ: Prentice-Hall, 1988. 
31. Porter, M. E. Competitive Strategy: Techniques for Analyzing Industries and Competitors. New York: Free Press, 1980.

32. Shaw, J. C. The Service Focus: Developing Winning Game Plans for Service Companies. Homewood, IL: Dow Jones-Irwin, 1990.

33. Schmidt, P. Frontier Production Functions. Econometric Reviews (1985).

34. Stabell, C. B., and Forsund, F. Productivity effects of computers in administration: an exploratory empirical investigation. Working Paper, Norwegian School of Economics and Business Administration (1983).

35. Weill, $P$. The relationship between investment in information technology and firm performance in the manufacturing sector. Unpublished Doctoral Dissertation. Stem School of Business, New York University (January 1989).

36. Weill, P., and Olson, M. Managing investment in information technology: min-case exsmples and implications. MIS Qwarterly (March 1989).

37. Zimmennan, W., ed. American Banker 1988 Managing Technology Survey: The Impact on the Bottom Line. New York: International Thompson Publishing Corp., 1988. 